\title{
Push-Pull Air Curtain Performances for VOCs Containment in an Industrial Process
}

\author{
A. Aubert and C. Solliec \\ GEPEA, DSEE, Ecole des Mines de Nantes, 4 rue Alfred Kastler, BP 20722, Nantes Cedex 03, France \\ Email:Camille.Solliec@emn.fr
}

(Received January 7, 2009; accepted September 21, 2009)

\begin{abstract}
The aim of this study is to analyze the efficiency of a Volatile Organic Compounds (VOCs) containment system using an air curtain (push-pull type) on a manual workstation. This work combines CFD numerical simulations of the air curtain system and experimental studies on a real scale test bench. The point is to evaluate whether the actual worker protection can be replaced by an air curtain system, without weakening human safety. The new system could considerably reduce energetic consumption (ventilation, heating) and VOCs emissions into the atmosphere. Experimental studies of the flow using a Particle Image Velocimetry anemometer (PIV) have been carried out to validate the numerical model kinematics. The containment quality obtained by the model has been validated with experimental concentration fields given by a gaseous analyzer using flame ionization (FID). Numerical simulation provides an overview of the containment efficiency in the global area of the system. Thus, it is possible to evaluate numerically, but accurately, the quality of the containment of the system. Moreover, an energetic study proves the economic benefit of the push-pull system.
\end{abstract}

Keywords: Air Curtain, Numerical Modeling, Experimentation, Large Scale PIV, FID analyze, Validation, Environmental protection, Energy saving.

\section{NOMENCLATURE}

$\begin{array}{ll}A & \text { Constant } \\ C & \text { Tracer concentration (ppmv) } \\ C_{\text {air }} & \text { Heat capacity }(\mathrm{J} /(\mathrm{kg} \mathrm{K})) \\ C_{m} & \text { Mean concentration of } \mathrm{C}_{2} \mathrm{H}_{6} \text { in steady } \\ & \text { state (ppmv) } \\ C_{\mu} & \text { Constant } \\ D_{n, m} & \text { Diffusivity of specie } \mathrm{n} \\ & \text { in the mixture } \mathrm{m}\left(\mathrm{m}^{2} / \mathrm{s}\right) \\ J_{n, i} & \text { Turbulent mass diffusion rate of } \mathrm{n} \\ & \text { specie on i direction }\left(\mathrm{kg} /\left(\mathrm{m}^{2} \mathrm{~s}\right)\right) \\ k & \text { Turbulent kinetic energy }\left(\mathrm{m}^{2} / \mathrm{s}^{2}\right) \\ P & \text { Pressure }(\mathrm{Pa}) \\ Q_{a s p} & \text { Suction flow }\left(\mathrm{m}^{3} / \mathrm{s}\right) \\ S c_{t} & \text { Turbulent Schmidt number } \\ t & \text { Time }(\mathrm{s}) \\ T_{i} & \text { Inside temperature }\left({ }^{\circ} \mathrm{C}\right)\end{array}$

\section{INTRODUCTION}

There has been a whole growing concern over sustainable development, health and ecology for few years now. As a consequence, the different standards, laws and emission limits are regularly restricted to reduce the impact of human activities on environment and human living conditions.

$\begin{array}{ll}T_{\text {ext }} & \text { Outside temperature }\left({ }^{\circ} \mathrm{C}\right) \\ U_{i} & \text { Mean velocity on i direction }(\mathrm{m} / \mathrm{s}) \\ V s & \text { Blowing velocity }(\mathrm{m} / \mathrm{s}) \\ x_{i} & \text { Coordinate in the i direction } \\ Y_{n} & \text { Mass fraction of } \mathrm{n} \text { specie } \\ \Delta p & \text { Pressure of aspiration }(\mathrm{Pa}) \\ \varepsilon & \text { Turbulence dissipation rate } \\ \rho & \text { Density of air }\left(\mathrm{kg} / \mathrm{m}^{3}\right) \\ \tau & \text { Time constant of the system }(\mathrm{s}) \\ \mu & \text { Dynamic viscosity }(\mathrm{Pa} \mathrm{s}) \\ \mu_{t} & \text { Turbulent viscosity }(\mathrm{Pa} \mathrm{s}) \\ C C D & \text { Charge Couple Device } \\ \text { ELV } & \text { Emission Limit Value } \\ F I D & \text { Flame Ionization Detector } \\ P I V & \text { Particle Image Velocimetry } \\ V O C s & \text { Volatile Organic }\end{array}$

Thus, companies are coerced to conform to these new constraints. This imposes an intense research to increase not only worker protection but also environment preservation.

The following study objective is to substitute the VOCs evacuation system used by a company. Concerning 
worker's protection the process is efficient but it is not in an energetic way and concerning environmental issues. An alternative system based on the air curtain principle is now considered. Air curtains are extensively used for thermal applications in order to separate two different temperature areas. The idea here is to use this barrier to keep volatile pollutants and to trap them. Poorly diluted VOCs are then treated by adsorption on filters made of activated carbon clothes.

Since the VOCs treatment process is already made and functional, the following work only focuses on the air curtain containment system. Using a numerical model validated with PIV measurement and thanks to gaseous analyses on a real scale test bench, the performance of such system can be highlighted.

A bibliographic study, pointed out some influent parameters of importance on the quality of the containment, such geometry, blowing velocity and aspiration flow Marzal et al. (2002a,b) and Huang et al. (2004).

\section{PROJECT DESCRIPTION}

The system currently set up in the company (Fig. 1a) is based on the extractor hood principle: a strong aspiration in the backside of the workstation (in front of the worker) provides protection against diffuse VOCs emanation.
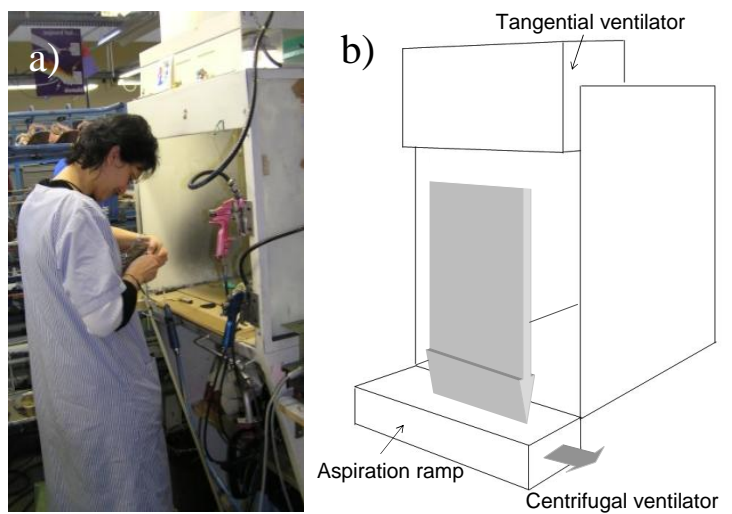

Fig. 1. a) Actuel workstation b) System studied.

Taking into account the previously mentioned reasons, the push-pull air curtain containment system (depicted on Fig. 1b) seems to be a good solution to reduce energetic cost and improve working conditions.

\section{NUMERICAL MODELING}

The push-pull air curtain system was numerically modeled to estimate the experimental parameters for the test-bench (i.e. blowing velocity and flow aspiration). Moreover, this model can be used in further applications to test a wide range of configurations.

\subsection{Theoretical Model}

It is assumed in this model that air is not compressible and the system is in a steady-state. The flow is turbulent, subject to recirculation inside the workstation and to high shear stresses in the jet area. Under these hypothesis, the mass conservation equation and the momentum equation (assuming the Boussinesq hypothesis) solved in this model are:

$\frac{\partial U_{i}}{\partial x_{i}}=0$

and

$U_{j} \frac{\partial U_{i}}{\partial x_{j}}=-\frac{1}{\rho} \frac{\partial P}{\partial x_{i}}+\frac{\partial}{\partial x_{j}}\left(\frac{\mu+\mu_{t}}{\rho} \frac{\partial U_{i}}{\partial x_{j}}\right)$

The closure system chosen is the K- $\varepsilon$ realizable model because it presents better agreements than a standard K$\varepsilon$ model in case of recirculating flow with high shear stresses. Its particularity is that the turbulent viscosity is calculated with a $\mathrm{C}_{\mu}$ coefficient (Cf Eq. 3) which is not considered as a constant but as a function of the flow. Another dissipation equation based on the dynamic equation of the mean-square vorticity fluctuation is also used.

$\mu_{t}=\rho C_{\mu} \frac{k^{2}}{\varepsilon}$

In order to evaluate the system containment efficiency, a tracer injection (ethane) with low velocity is put in the bottom of the workstation to simulate VOCs emission in the hood. It is assumed here that this velocity doesn't disturb the flow significantly. This will be checked out in subsection 4.1. The numerical model thus solves the following species transport equations:

$\frac{\partial}{\partial x_{i}}\left(u_{i} Y_{n}\right)=-\frac{\partial}{\partial x_{i}} J_{n, i}$

with

$J_{n, i}=-\left(\rho D_{n, m}+\frac{\mu_{t}}{S c_{t}}\right) \frac{\partial Y_{n}}{\partial x_{i}}$

where $\mathrm{J}_{\mathrm{n}, \mathrm{i}}$ is the mass diffusion rate in a turbulent flow.

Concerning geometry, the workstation is reproduced in a full scale 3D to take into account the three dimensional effects which could have high impact on the containment quality. Two geometric configurations have been studied. They only differ in the location of the aspiration and were selected because of their ease of implementation in the real workstation (Cf. Fig. 2).

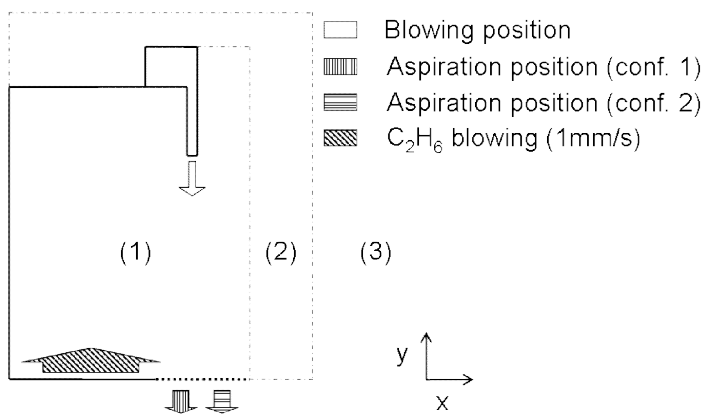

Fig. 2. Schematic representation of boundary conditions and meshes 


\subsection{Boundary Conditions}

Boundary conditions (See Fig. 2) concerning velocities are as follow:

- a constant velocity Vs is imposed on the blowing surface nozzle.

- a diffuse ethane injection $\left(\mathrm{Y}_{\mathrm{eth}}=1\right)$ is set in the bottom of the workstation with a low velocity (1 $\mathrm{mm} / \mathrm{s}$ ).

The walls of the workstation are modeled with a near wall method (two-layer model) resolving thus the viscous sublayer.

A constant pressure condition $(\Delta p)$ is imposed on the suction ramp. Finally, a null relative pressure is set for the computational domain boundaries located far from the workstation.

\subsection{Mesh}

The computational domain is divided into three different mesh areas (Cf. Fig. 2). Inside the workstation and close to the jet (1), the mesh is thin and structured because of the importance of velocity gradients. In the close neighborhood of the first area (2), the mesh is thin and unstructured. Finally in the rest of the computational domain (3) the mesh is unstructured with cell size increasing when straying from the workstation. This model uses 800000 cells.

\subsection{Numerical Schemes}

Equations presented in subsection 2.1 are solved using a first order discretization scheme. The coupling between pressure and velocity is calculated with the SIMPLE algorithm. The calculations are done with a double precision.

\section{MATERIAL AND METHODS}

In order to validate the numerical model, a test bench which reproduces exactly the workstation dimensions was built. Only few adjustments were made to enable experiments and to add the push-pull system.

\subsection{The Push-Pull System}

The air flow is generated by a tangential ventilator located at the top of the workstation. Then the flow is channeled with a thin nozzle to initiate the air curtain. The power supply was measured for different blowing velocities. The results are presented in Table 1 .

Table 1 Power supply vs. jet velocity

\begin{tabular}{|l|c|c|c|c|}
\hline Velocity (m/s) & 1 & 1.5 & 2 & 2.4 \\
\hline Power supply (W) & 8.6 & 9.4 & 10.8 & 11.5 \\
\hline
\end{tabular}

In order to provide the most homogeneous aspiration flow over the workstation length, a ramp divided into three compartments was designed, as the centrifugal ventilator is only located on one side of the ramp. A $190 \mathrm{~W}$ power supply was measured for an aspiration flow $\mathrm{q}_{\text {asp }}=330 \mathrm{~m}^{3} / \mathrm{h}$. As mentioned in subsection 2.1, the system can be positioned whether inside or outside the workstation.

\subsection{The PIV System}

The PIV system is composed by a double $50 \mathrm{~mJ}$ YAG laser, synchronized with a high resolution Kodak Megaplus CCD camera. Because of the high size of the recorded field $\left(>1 \mathrm{~m}^{2}\right)$ correlations are obtained by a comparison between smoke coherent structure motions (in grey level) ; technique called high scale PIV Planquart and Riethmuller (2006).This technique requires a larger laser beam than the classical PIV. This allows catching the slightly three-dimensional smoke structures. Moreover interrogation windows must be enlarged because turbulent structure dimensions are more important than particle ones used in classical PIV.

The use of PIV system implies few modifications of the workstation: one side was deputised with Plexiglas to be able to film the lightened area. Furthermore a thin slot of the backside of the hood was replaced with Plexiglas to enable lightening from the back (see Fig. 3).

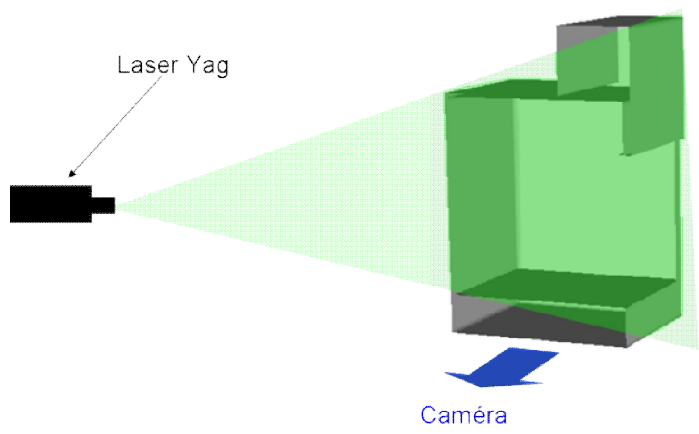

Fig. 3. PIV system organization

Flow seeding for PIV is realised with cold smoke injected both in the jet and outside the containment area.

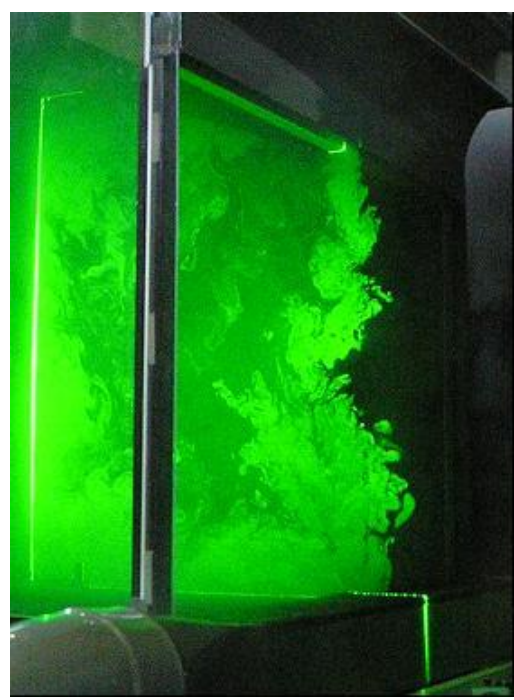

Fig. 4. Flow visualization by laser tomography (seeding in the jet) 
Figure 4 shows an example of visualization obtained by laser tomography in the test bench. Only a jet seeding is used here and the aspiration is located outside the workstation (configuration 2).

The jet can clearly be seen on the right side of the picture. Kelvin-Helmholtz coherent structures can be observed in the mixing layer. One part impacts the bottom of the test bench, inducing thus a convection motion. The other part is sucked by the ramp. No smoke seems to escape from the jet boundary which can also be observed with a seeding inside the workstation.

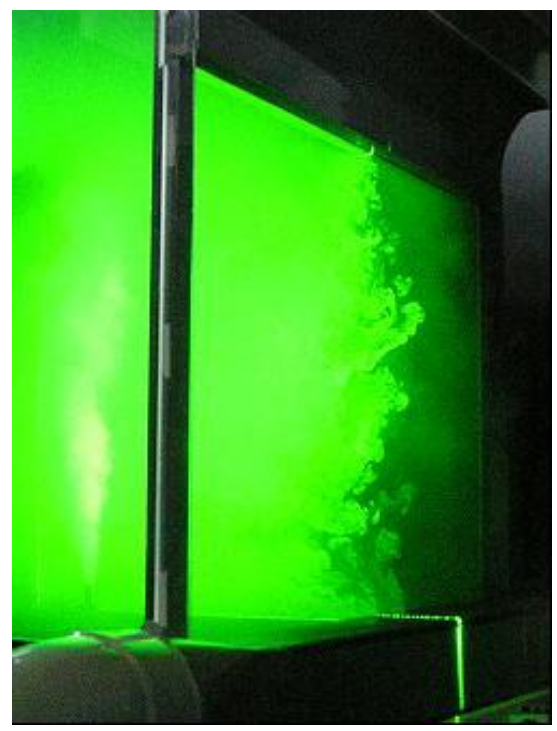

Fig. 5. Flow visualization by laser tomography (seeding inside the workstation)

On Fig. 5, the flow is seeded inside the workstation in configuration 2 . It can be noticed that no smoke leaves the containment area or it is totally aspired. This confirms the idea of using an air curtain to trap VOCs inside the hood. Moreover the over-pressure inferred by the seeding doesn't seem to affect strongly the system behavior.

\subsection{The FID System}

To quantify containment efficiency, an analysis using gas tracing was realized on the same test bench, requiring few modifications. For example, a homogeneous $\mathrm{C}_{2} \mathrm{H}_{6}$ injection system with low velocity was implemented in the bottom of the test bench (as shown in Fig. 6). This system uses thin grids in order to reduce turbulence. A porous material was used to have the most diffuse injection on the bottom surface. Moreover stems were set inside and outside the workstation to maintain the FID probes.

The $\mathrm{C}_{2} \mathrm{H}_{6}$ concentration is measured in the symmetry plane of the workstation as a function of the $\mathrm{X}$ horizontal position. A probe located at $20 \mathrm{~cm}$ from the workstation far end is taken as the reference concentration in the hood.

The other probe is used to measure the concentration when straying from the inside to the outside.
Figure 7 is an example of result obtained with the analyzer for a probe located $8 \mathrm{~cm}$ outside from the blowing nozzle $(\mathrm{Cm}$ represents the mean value of the concentration in a steady state) with $\mathrm{Vs}=1.5 \mathrm{~m} / \mathrm{s}$ and an aspiration flow $\mathrm{q}_{\mathrm{asp}}=330 \mathrm{~m}^{3} / \mathrm{h}$.

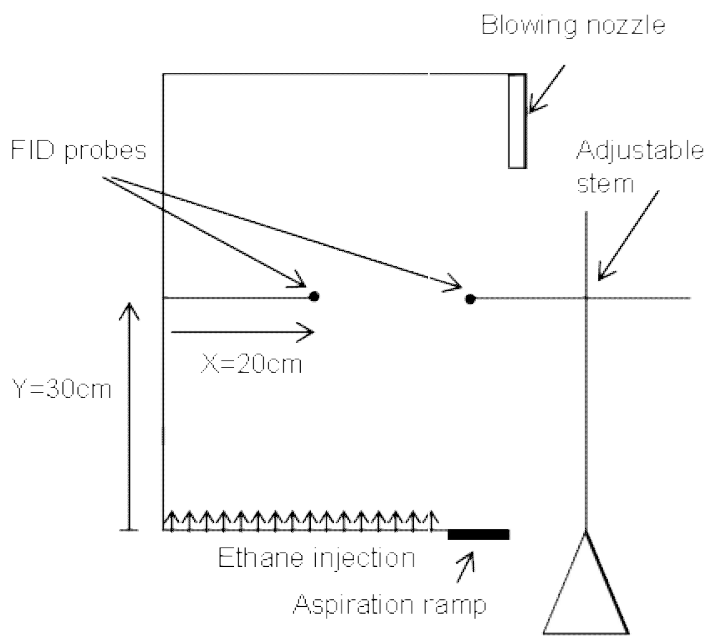

Fig. 6. FID system organization

The measures can be distinguished into three different phases: a phase where the concentration increases (corresponding to the beginning of the ethane injection), an established phase where the concentration is roughly steady and a decreasing phase (due to the interruption of the ethane injection). The transient phases are quite short: they only last one minute. The difference between the reference probe and the probe located outside the air curtain is very clear. By averaging the different values during the steady state, it appears that the concentration in the measurement point (at $8 \mathrm{~cm}$ from the external lip of the blowing nozzle) represents only $2 \%$ of the internal concentration.

\subsection{Time Constant of the System}

Another important result which can be taken from the FID analyzer is the time constant of the push-pull system. Indeed it is important to know how long does the system take to empty itself since the pollution source is turned off. On Fig. 7 it can be noticed that once the ethane injection is stopped a quick decrease of concentration in the workstation can be observed.

A mass balance in transient state allows calculating the time constant $(\tau)$ of the system with a decreasing law (Cf. Eq. (6)).

$$
\frac{\mathrm{C}}{\mathrm{C}_{\mathrm{m}}}=A e^{-\frac{t}{\tau}}
$$

or:

$$
\operatorname{Ln}\left(\frac{\mathrm{C}}{\mathrm{C}_{\mathrm{m}}}\right)=\operatorname{Ln}(A)-\frac{t}{\tau}
$$

Thus, the slope of the curve is the inverse of the time constant. It can also be interpreted as the ratio of air renewal contained in the hood.This curve is represented in Fig. 8. 


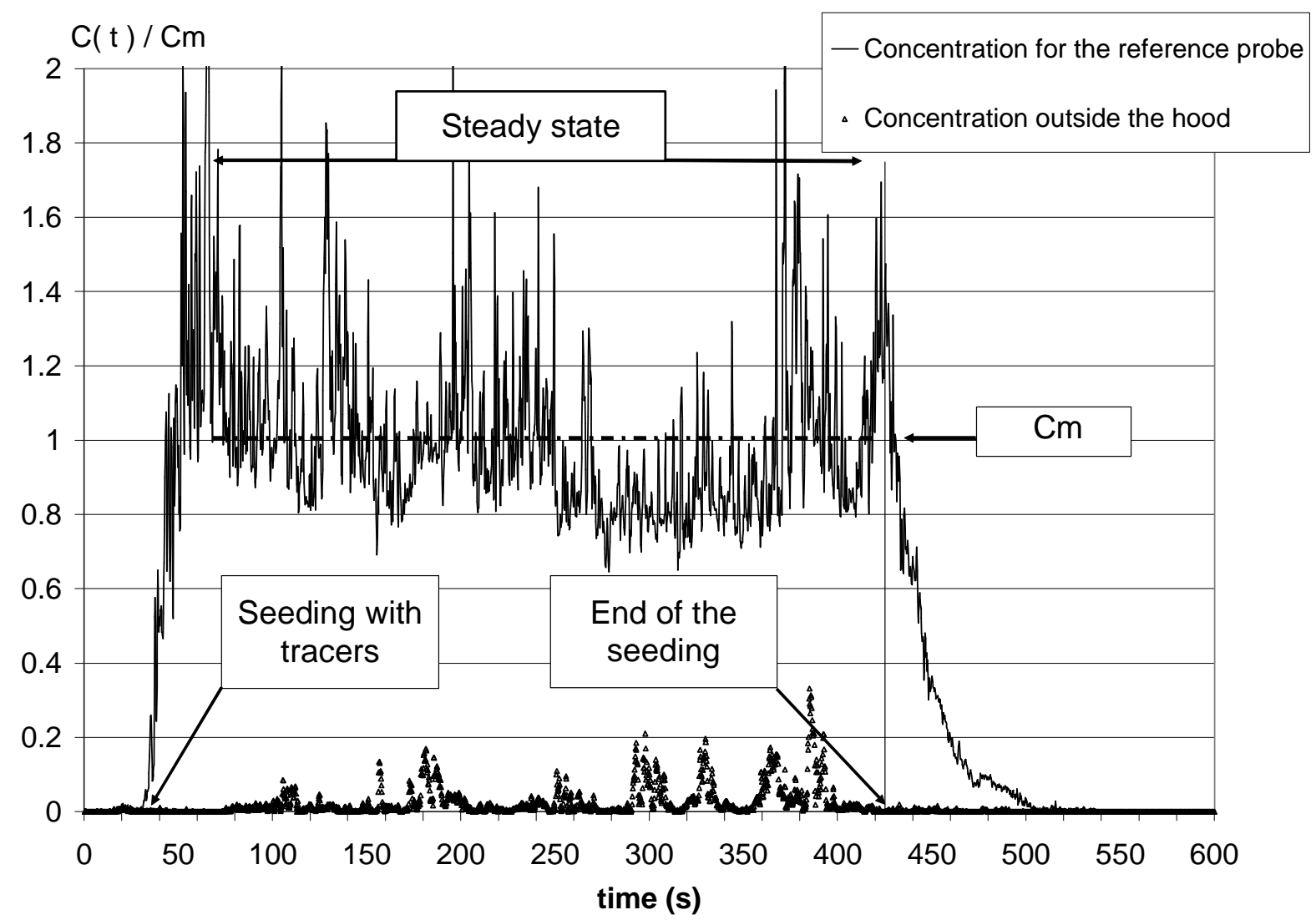

Fig. 7. Example of FID measurement (with a probe located $8 \mathrm{~cm}$ outside the workstation)

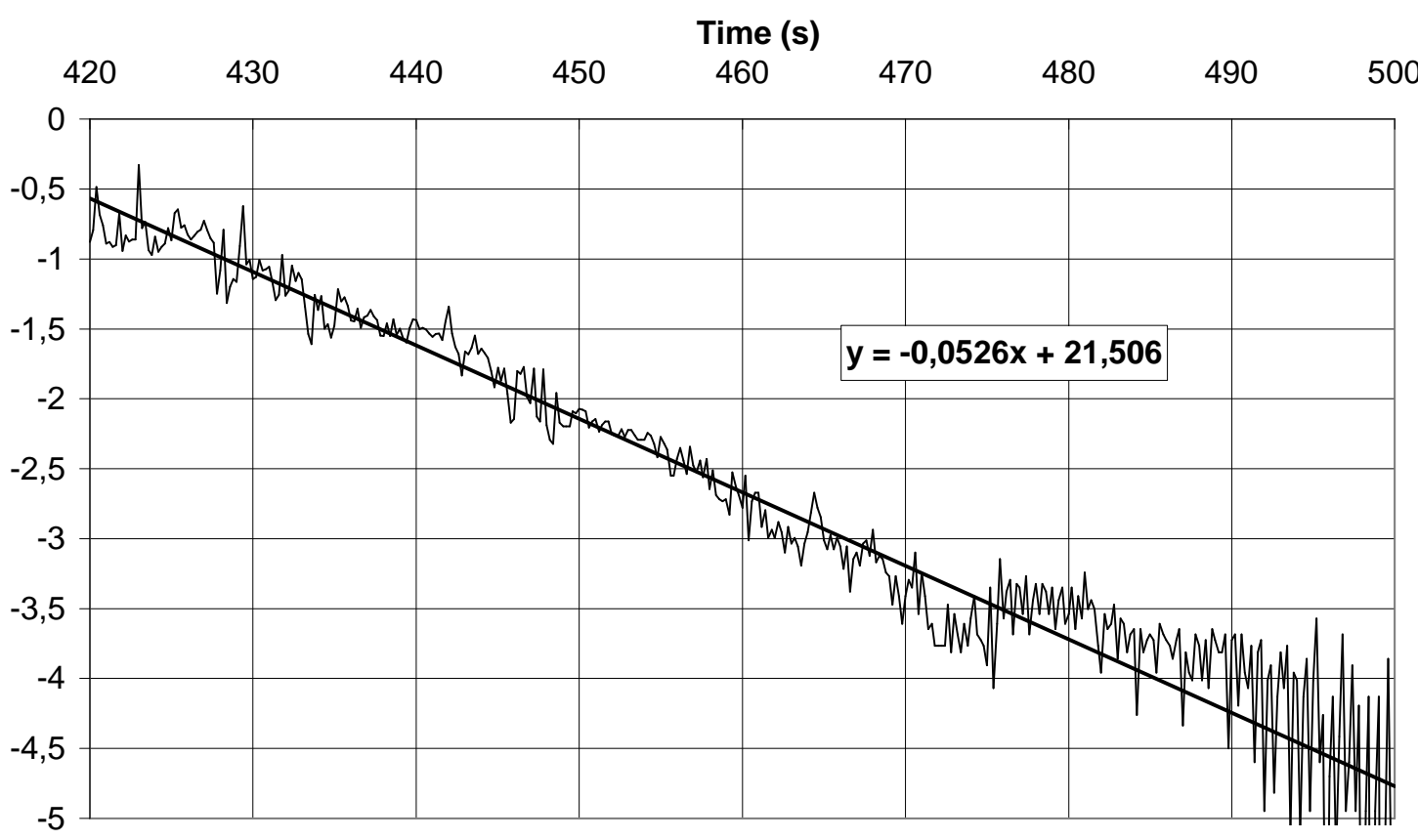

$\operatorname{Ln}(\mathbf{C}(\mathbf{t}) / \mathbf{C m}$

Fig. 8. $\mathrm{Ln}(\mathrm{C}(\mathrm{t}) / \mathrm{Cm})$ vs. time during the emptying phase 
By applying a linear regression, it can be found that $\tau$ $=25 \mathrm{~s}$. So the concentration in the workstation can be considered as nearly null after $4 \tau$ (characteristic for first order systems) which corresponds to $100 \mathrm{~s}$.

\section{RESUltS AND DisCUSSIONS}

Before detailing the model outcomes, the results are first compared to the experimental data. This could be, also, used to have a better understanding of the associated physics.

\subsection{Validation of the Kinematics}

The kinematics results obtained with simulations and with experiments are displayed in this subsection in parallel so as to ensure the accordance between both results.

Figure 9 represents the streamlines obtained by the PIV (left) and by calculations (right). The parameters used in this comparison are $\mathrm{Vs}=1.5 \mathrm{~m} / \mathrm{s}$ and $\Delta \mathrm{p}=1.5 \mathrm{~Pa}$ (this depression corresponds to $\mathrm{q}_{\text {asp }}=330 \mathrm{~m}^{3} / \mathrm{h}$ ).

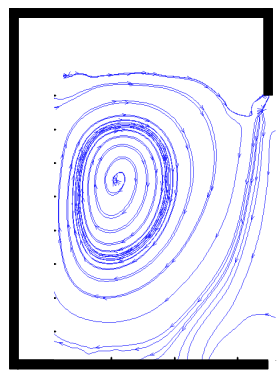

a)

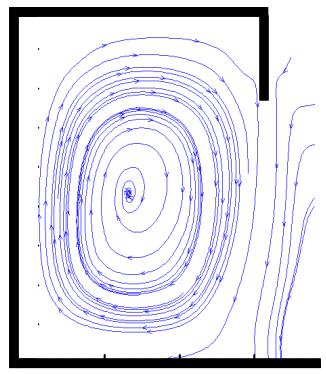

c)

Fig. 9. Experimental $(a, c)$ and numerical $(b, d)$ streamlines for configuration $1(\mathrm{a}, \mathrm{b})$ and $2(\mathrm{c}, \mathrm{d})$ $\left(\mathrm{Vs}=1.5 \mathrm{~m} / \mathrm{s}\right.$ and $\left.\mathrm{q}_{\text {asp }}=330 \mathrm{~m}^{3} / \mathrm{h}\right)$

It appears that in the experiments (Fig. 9a and c) the streamlines can't be obtained on the entire measurement field. This is mostly linked to optical difficulties (shadow area), but it may also be due to the high scale PIV technique. Indeed in some areas the contrast between grey levels was not sufficient to obtain a good correlation (probably related to the turbulent diffusion).

Concerning the global behavior, the kinematics fields in the experiment and in the simulation are relatively close (both for the jet and the recirculation area). However, the aspiration seems to be more important in the simulation. This can be explained by the difficulty in obtaining a homogeneous aspiration all along the ramp. In addition, it clearly appears that the low flow of ethane in the bottom of the workstation model has little influence on the flow kinematics. There is just a slight vertical offset of the calculated streamlines. The aspect of the kinematics of the model can thus be considered as validated.

\subsection{Validation of the Containment Efficiency}

In a second time, the numerical model has to be validated concerning its ability to model pollutant containment. In this purpose, the CFD results are presented in parallel with those obtained experimentally through the FID analyzer.

The measure and the calculation detailed in subsection 3.3 allow comparing the local efficiency of the experimental device with the numerical one. This pattern is repeated for different $X$ values. Results in the medium plan of the workstation are depicted in Fig. 10 (first configuration) and in Fig. 11 (second configuration).

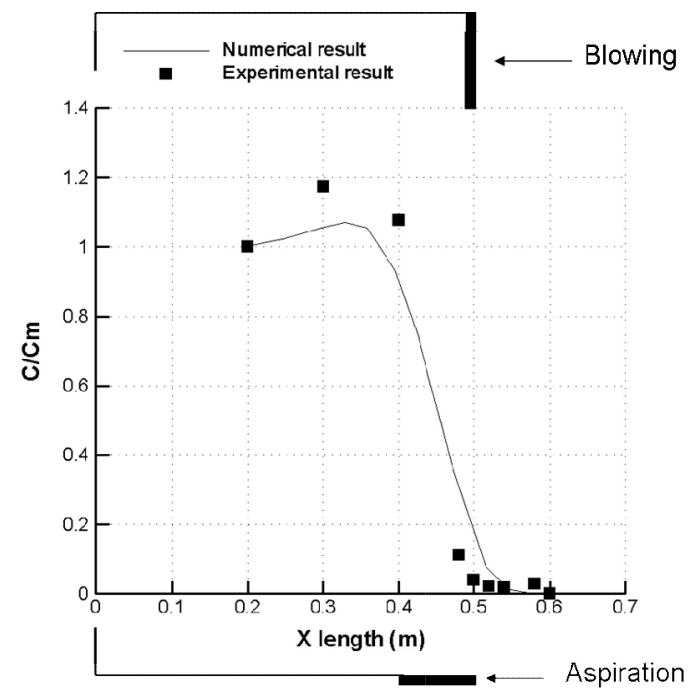

Fig. 10. $\mathrm{C} / \mathrm{Cm}$ vs $\mathrm{X}(\mathrm{Y}=30 \mathrm{~cm})$ in configuration 1 $\left(\mathrm{Vs}=1.5 \mathrm{~m} / \mathrm{s}\right.$ and $\left.\mathrm{q}_{\mathrm{asp}}=330 \mathrm{~m}^{3} / \mathrm{h}\right)$

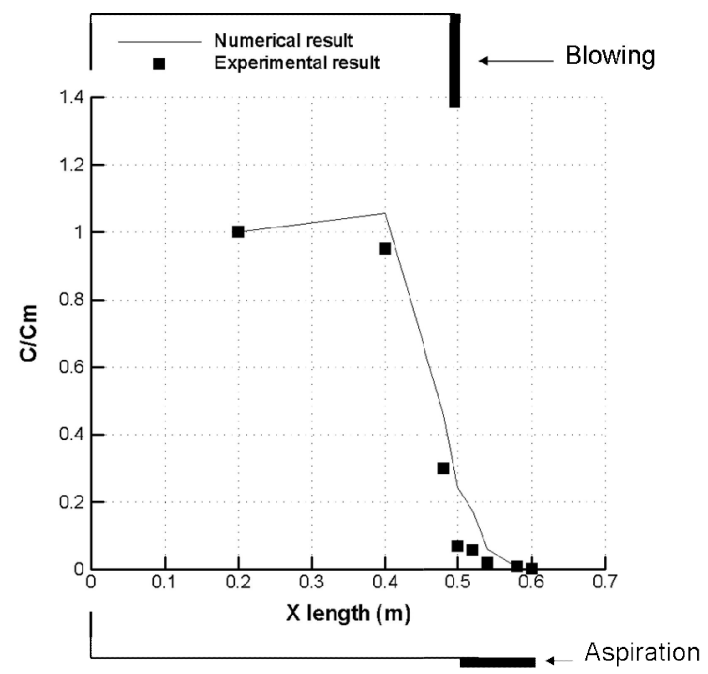

Fig. 11. $\mathrm{C} / \mathrm{Cm}$ vs $\mathrm{X}(\mathrm{Y}=30 \mathrm{~cm})$ in configuration 2 $\left(\mathrm{Vs}=1.5 \mathrm{~m} / \mathrm{s}\right.$ and qasp $=330 \mathrm{~m}^{3} / \mathrm{h}$ ) 
The correlation between experimental and numerical results is quite good. These results show a good tendency of the air curtain to contain pollutant as the fraction of ethane outside the workstation is relatively low. (An experimental problem didn't allow to display the measurement of the point $(\mathrm{X}=0.3 \mathrm{~m})$ in the second configuration (Fig. 11).)

According to the above subsections, the model can be considered as validated on kinematics and mass transfer point of views (containment efficiency). The model can now be used to evaluate the total field of mass fraction and to perform parametrical analyses of our containment system.

\subsection{Numerical Study}

Now that the numerical model is validated, it can be used to have a more general understanding of the air curtain system efficiency. Indeed, on Fig. 12 (configuration $1, \mathrm{Vs}=1.5 \mathrm{~m} / \mathrm{s}$ and $\mathrm{q}_{\mathrm{asp}}=330 \mathrm{~m}^{3} / \mathrm{h}$ ) the mass fraction of ethane leaving the workstation is globally low (lower than 0.025 in a plan located at $2 \mathrm{~cm}$ of the external lip of the blowing nozzle, that is the plane $X=0.52$ ).

It can also be noticed that the slope of the VOCs mass fraction vs $X$ functions is relatively sharp in the neighborhood of the jet $(0.4<\mathrm{X}<0.5)$. This reinforces the idea of a fluid barrier created by the jet.

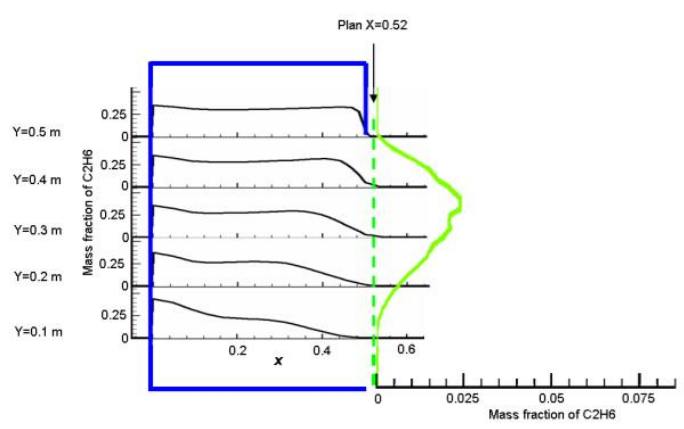

Fig. 12. Numerical mass fraction field for configuration $1\left(\mathrm{Vs}=1.5 \mathrm{~m} / \mathrm{s}\right.$ and $\left.\mathrm{q}_{\mathrm{asp}}=330 \mathrm{~m}^{3} / \mathrm{h}\right)$

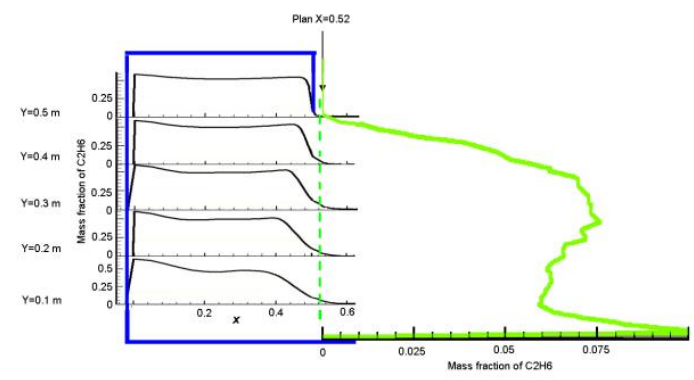

Fig. 13. Numerical mass fraction field for configuration $2\left(\mathrm{Vs}=1.5 \mathrm{~m} / \mathrm{s}\right.$ and $\left.\mathrm{q}_{\mathrm{asp}}=330 \mathrm{~m}^{3} / \mathrm{h}\right)$

Note that the feeling of a worse concentration in Fig. 13 for the plane $X=0.52$ is due to the location of the aspiration. Indeed the containment area is enlarged compared to the first configuration. Thus results concerning the first centimeters outside the workstation are not relevant regarding efficiency as located in the containment area.

The fact that the VOCs mass fraction vs $\mathrm{X}$ functions decreases quickly, shows that the jet still acts as a barrier in this configuration.

Generally, it can be concluded, according to the numerical results that the air curtain system provides a good VOCs containment quality in the whole area of the workstation. In addition, these performances are valid for both configurations.

\subsection{Study on the Energetic Gain}

For safety and hygiene reasons, industries which use VOCs often renew air frequently to dilute pollutants over the prescribed level: Emission Limit Value (ELV). However the use of a high renewal rate leads to important sensible energetic losses. Indeed, as workshops are heated to provide good working conditions, air renewal, even with double flow ventilation with heat exchanger, induces thermal losses.

Since the air curtain system has proved its efficiency in terms of pollutant containment, it could allow reducing air renewal rate without affecting air quality inside the workshop. That is why, energetic loss induced by the use of both systems (the actual and the air curtain one) are compared here. It is currently assumed that the energetic consumption related to the working of the push-pull system, that means the two ventilators (approximately $200 \mathrm{~W}$, see subsection 3.1), is negligible compared to the energy wasted by extracting heated air from the workshop. The same assumption is made concerning the aspiration device in the extractor hood configuration.

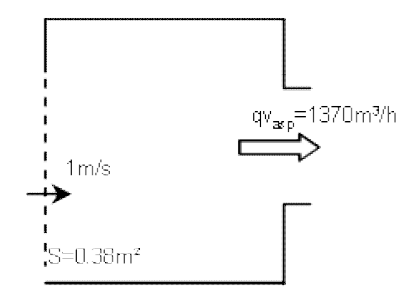

Actual system

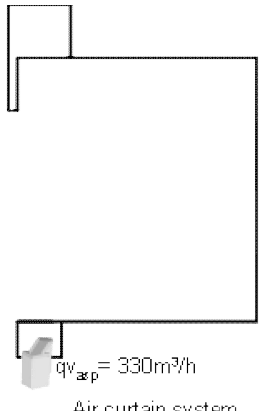

Air curtain system
Fig. 14. Comparison of both systems

The energy loss due to air renewal considering those hypothesis is given by Eq. (8):

$P_{\text {Lost }}=\rho \quad q_{\text {asp }} \quad C_{\text {air }} \quad\left(T_{i}-T_{\text {ext }}\right.$

If both systems are considered to work in the same environmental conditions, the difference between them is only in the aspiration flow rate. Indeed $\rho, C_{a i r}, T_{i}$ and $\mathrm{T}_{\text {ext }}$ are independent of the chosen system but depend on air properties, ambient conditions and imposed temperature inside the workshop.

The aspiration flow in the extractor hood configuration was estimated through a mean velocity measurement with a hot wire anemometer. Knowing the area (See 
Fig. 14) comes a $1370 \mathrm{~m}^{3} / \mathrm{h}$ flow; to be compared to the $330 \mathrm{~m}^{3} / \mathrm{h}$ flow measured for the air curtain system.

$$
\frac{q_{\text {asp ,extractor }}}{q_{\text {asp , air curtain }}}=4.6
$$

In this situation, the air curtain divides by more than 4.5 the energy wasted by rejection to the atmosphere $(\mathrm{Cf}$ Eq. (9)).

In addition the total energetic consumption will be evaluated over a year for both systems, in order to quantify the gain induced by the air curtain system on the industrial site. The power supply of the ventilation systems is now included. The consumption is calculated, with a one hour time step. It takes into account the five hoods of the industrial workshop, working eight hours a day, five days a week except on holidays. The external temperature is taken from meteorological data concerning the industrial site. The internal temperature is set to $18^{\circ} \mathrm{C}$.

Results are depicted on Fig. 15.

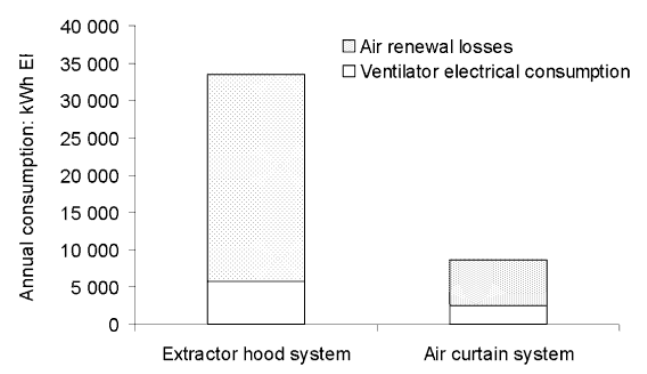

Fig. 15. Annual energetic consumption for each system

It appears that the air curtain system can reduce the global working cost by 3.9. Moreover the air curtain device reduces the air flow circulating around the operator, which is good to improve working conditions.

\section{CONClusion}

This study proves the reliability of the numerical model of the air curtain in a containment application. This validation was made with respect to kinematics fields by PIV measurements and concentration fields by gaseous tracer measurements (FID).

Those experiments allow estimating the time constant of the system which is the average time of residence of VOCs in the hood.
Once validated, the numerical model permits a better understanding of the global containment quality. This model could thus be used in a future parametric study of the containment efficiency, estimating the influence of geometry and blowing velocity and aspiration flow. Thereafter, an optimal configuration of such system could be found taking into account the best containment for the least energetic cost.

Except from the energetic performance, the operators' protection and the better working conditions provided, this system improves the environmental aspect of the process. Indeed, the flow needed by the system allows the adsorption of VOCs on the activated carbon tissue filters.

\section{ACKNOWLEDGEMENTS}

This study was realized in the context of a research convention in collaboration with the BOPLAN Engineering and SAMSON companies and was financed by the ADEME.

\section{REFERENCES}

Huang, R.F., S.Y. Lin, S.Y. Jan, R.H. Hsieh, Y.K. Chen, C.W. Chen, W.Y. Yeh, C.P. Chang, T.S. Shih and C.C. Chen (2004). Aerodynamic Characteristics and Design Guidelines of Push-Pull Ventilation Systems. Annals of Occupational Hygiene, 1475-3162.

Marzal, F., E. González, A. Miñana and A. Baeza (2002a). Influence of Push Element Geometry on the Capture Efficiency of Push-Pull Ventilation Systems in Surface Treatment Tanks. Annals of Occupational Hygiene 46, 383-393.

Marzal, F., E. González, A. Miñana and A. Baeza (2002b). Determination and Interpretation of Total and Transversal Linear Efficiencies in Push-Pull Ventilation Systems for Open Surface Tanks. Annals of Occupational Hygiene 46, 629-635.

Planquart, P.H. and M.L. Riethmuller (2006). Adaptation de la technique PIV à l'étude d'écoulements à grande échelle. Congrès Francophone de Techniques Laser (CFTL). 